\title{
Economic impact of a rotavirus vaccination program in Mexico
}

\author{
Dagna Constenla, ${ }^{1}$ F. Raúl Velázquez, ${ }^{2}$ Richard D. Rheingans, ${ }^{1}$ \\ Lynn Antil, ${ }^{1}$ and Yolanda Cervantes ${ }^{3}$
}

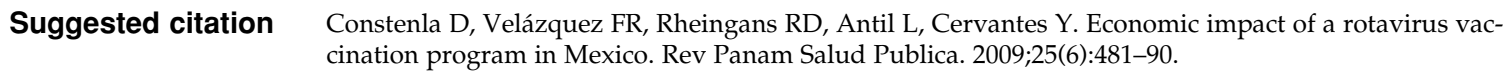

ABSTRACT Objectives. To evaluate the cost and benefits of a national rotavirus childhood vaccination program in Mexico.

Methods. A decision-analysis model was designed to take the Mexican health care system's perspective on a comparison of two alternatives: to vaccinate against rotavirus or not. Using published, national data, estimations were calculated for the rotavirus illnesses, deaths, and disability-adjusted life years (DALYs) that would be averted and the incremental costeffectiveness ratios (US\$/DALY) of a hypothetical annual birth cohort of 2285000 children, with certain assumptions made for cost, coverage, and efficacy rates.

Results. With 93\% coverage and a vaccine price of US\$ 16 per course (2 doses), a rotavirus vaccination program in Mexico would prevent an estimated 651 deaths (or 0.28 deaths per 1000 children); 13833 hospitalizations (6.05 hospitalizations per 1000 children); and 414927 outpatient visits (182 outpatient visits per 1000 children) for rotavirus-related acute gastroenteritis (AGE). Vaccination is likely to reduce the economic burden of rotavirus AGE in Mexico by averting US\$ 14 million (71\% of the overall health care burden). At a vaccine price of US\$ 16 per course, the cost-effectiveness ratio would be US\$ 1139 per DALY averted. A reduction in the price of the rotavirus vaccination program (US\$ 8 per course) would yield a lower incremental cost-effectiveness ratio of US\$303 per DALY averted.

Conclusions. A national rotavirus vaccination program in Mexico is projected to reduce childhood incidence and mortality and to be highly cost-effective based on the World Health Organization's thresholds for cost-effective interventions.

Key words Rotavirus, rotavirus vaccines, cost-benefit analysis, mass immunization, gastroenteritis, Mexico.

1 Department of Global Health, Rollins School of Public Health, Emory University, Atlanta, Georgia, United States of America. Send correspondence to: Dagna Constenla, Ph.D., Department of Global Health, Rollins School of Public Health, Emory University, Atlanta, GA, USA; telephone/fax: +01970-266-1153; e-mail: dagnaconstenla@yahoo.com

2 Unidad de Investigación Médica en Enfermedades Infecciosas y Parasitarias, Hospital de Pediatría, Centro Médico Nacional Siglo XXI, Instituto Mexicano del Seguro Social, Ciudad de México, DF, México.

3 GlaxoSmithKline Biologicals S.A., Mexico City, Mexico.
Rotavirus is a virus that infects the small intestine and can lead to lifethreatening acute gastroenteritis (AGE) in infants and young children worldwide. Unlike many other enteropathogens, rotavirus affects children in both developed and developing countries, regardless of socioeconomic status (1, 2 ). However, the risk of dying from rotavirus-related gastroenteritis (GE) is greater in lower-income countries due to various factors, including limited access to health care facilities, lower mean age at contraction, and malnutrition. Due to the widespread nature of rotavirus, its high concentration in the feces, and its ability to survive in the environment, the prevention of rotavirus spread is virtually impossible, even where the highest hygiene standards are followed (2).

In Mexico, rotavirus is one of the principal causes of GE and occurs mainly 
during the fall and winter months. It is of particular concern in pediatric hospitals, emergency rooms, and outpatients clinics. However, improved availability of potable water, access to oral rehydration therapy, and enhanced surveillance of all diarrheal episodes have reduced the overall burden of GE in young children (3). Morbidity rates associated with all diarrheal diseases decreased from 4588 per 100000 children under 5 years of age in 1999 to 3383 by 2002, with the greatest reduction observed among those under 1 year. There has also been a significant decrease in severe diarrheal episodes among children under 5 years of age, from 24.8 per 100 hospitalizations in 1990 to 9.2 in 1995. This represents a $63 \%$ reduction (3) and is the most accurate information to date. Overall mortality due to AGE in children under 5 years also decreased from 125.3 per 100000 in 1990 to 19.7 by 2002, an $84 \%$ reduction (3). From 1990-2002, a significant reduction in mortality was observed in AprilAugust, from 13.4 per 100000 children under 5 years in 1990 to 1.6 in 2002 (3).

While overall GE morbidity and mortality have declined, the proportion attributable to rotavirus appears to be increasing $(3,4)$. The highest mortality rates for children under 1 year coincided precisely with the fall and winter season. A retrospective, cross-sectional study of 15 large cities in Mexico reported that, annually, $42 \%$ of the children seeking AGE treatment at pediatric hospitals were rotavirus positive (3).

This paper presents detailed analyses of the disease burden and costs of rotavirus disease among Mexican children, and the expected cost-effectiveness of introducing a national rotavirus vaccination program. These results are part of a larger study being carried out in Latin America and the Caribbean, specifically Argentina, Brazil, Chile, Dominican Republic, Honduras, Mexico, Panama, and Venezuela $(5,6)$. In contrast to this Regional study, in which estimates were derived from extrapolated data, this paper focuses solely on Mexico and uses country-level epidemiological data and cost estimates.

\section{MATERIALS AND METHODS}

\section{Analytic overview}

A diagram of the model used to estimate the economic burden and cost-

\begin{abstract}
FIGURE 1. Model framework depicting rotavirus (RV) vaccine introduction and subsequent events that may be experienced by each child, including life-years gained (LYG) and disability-adjusted life years (DALYs)
\end{abstract}

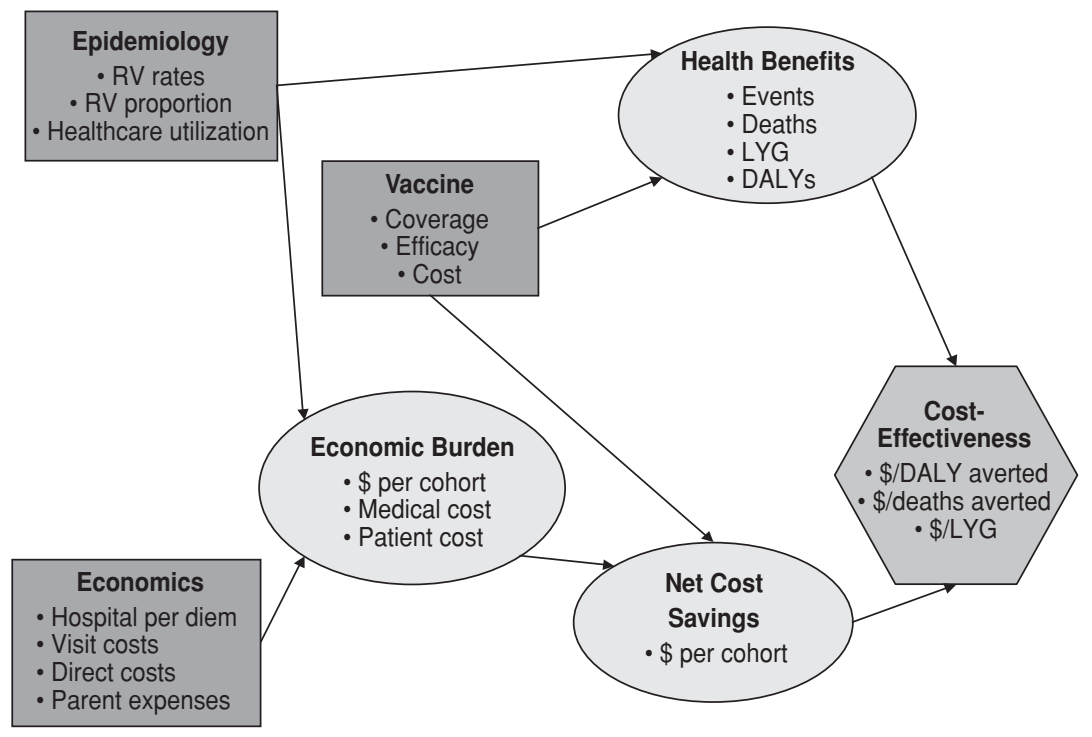

effectiveness of rotavirus vaccination is shown in Figure 1. The boxes identify the primary inputs needed for the model (epidemiological, economic, and vaccine data). The circles represent the intermediary outputs (health benefit, economic burden, and net cost savings). The primary outputs of the model are displayed in hexagons as cost-effectiveness ratios. In this study, these ratios are expressed as the cost per death averted, per disabilityadjusted life years (DALYs) averted, or per life year gained (LYG). This diagram provides only a broad representation of the inputs and outputs of the model.

A decision-analysis model was developed in Microsoft Excel ${ }^{\circledR}$ to estimate the health and economic outcomes of a national rotavirus vaccination program in a hypothetical annual birth cohort of children for a 5-year period. The net, medical, direct-cost of the vaccination program was determined to be the cost of the vaccination program, minus the expected averted medical costs (the savings from reduced use of health care resources).

The primary perspective for this analysis was that of the health care system. Costs such as non-medical direct costs or productivity losses to caregivers were not included in these cost-effectiveness calculations due to paucity of data. All cost estimates collected in local currency were converted to 2007 United States dollars (US\$). Future costs and
DALY estimates were discounted at a $3 \%$ rate, as recommended by the U.S. Panel of Cost-Effectiveness in Health and Medicine (7) and the World Bank Global Burden of Disease Project (8).

The annual birth cohort considered was 2285000 children (9). The age distribution of rotavirus illness was estimated for each one of the disease outcomes (deaths, hospitalizations, and outpatient visits) using published studies from Mexico and Latin America (1020). The estimated number of outcomes for an annual birth cohort was distributed as follows: $0-2$ months of age, 3-5, $6-8,9-11,12-23,24-35,36-47$, and 48-59.

\section{Model inputs}

Rotavirus disease burden. Disease burden was estimated as the expected number of rotavirus-associated outcomes for a single birth cohort. The risk of rotavirus-related outpatient visit, hospitalization, and death were based on the cumulative risk of each AGE event during the first 5 years of life and the proportion of these events attributed to rotavirus. The cumulative risk of each event in Mexico was estimated from national administrative data for the year $2002(21,22)$, and refers to the proportion of children in a defined population infected with rotavirus at least once before reaching their 5 th year of life. Risk refers to the proportion of a population for an 
event and cumulative is the risk for each year of age multiplied together.

In brief, the cumulative risk of a rotavirus outpatient visit was calculated using data provided by the epidemiology unit of the Instituto Mexicano del Seguro Social (Mexican Social Security Institute, IMSS). The IMSS reported a total of 950231 emergency room/outpatient visits for diarrhea among children less than 10 years of age, of which an estimated $93 \%$ were in children less than 5 years (22). In addition, in 2002, the Statistics and Information Division of the Secretaría de Salud/Servicio Social de Salud (Secretary of Health and Social Services, SSA), reported 974129 outpatient visits for the same age group (21). To calculate the 5-year cumulative risk of an outpatient visit for diarrhea, the total number of diarrheal outpatient visits for children less than 5 years $(883715+974129=1857844)$ was divided by the proportion of Mexico's total under-1 year population (2 056 853). The rotavirus-specific outpatient rate was then calculated assuming that $25 \%$ of diarrheal outpatient visits were attributed to rotavirus. This was an average estimate based on data from five published studies (23-26). The cumulative risk of an outpatient visit for rotavirus AGE (265 per 1000 ) was calculated by multiplying the cumulative risk of an outpatient visit for AGE by the proportion attributed to rotavirus GE.

The cumulative risk of rotavirus AGE hospitalization was based on national data for the year $2002(21,22)$, using codes A00-A09 of the International Classification of Diseases, 10th Edition (27). The SSA reported 15513 hospitalizations for diarrhea among children less than 5 years of age. In addition, the IMSS reported a total of 16347 diarrheal hospitalizations for children less than 10, of which $93 \%$ occurred in children less than 5 . The number of children less than 5 years of age hospitalized for diarrhea (30 716) was then divided by the population less than 1 year (2 056 853) covered by both health care systems. The cumulative risk of diarrheal hospitalization was 0.0176 per child by the 5 th birthday. The rotavirus proportion $(40 \%)$ was based on published estimates $(3,28)$. The cumulative risk of hospitalization for rotavirus AGE (7 per 1 000) was then calculated by multiplying the cumulative risk of AGE hospitalization by the proportion attributed to rotavirus AGE.
The cumulative risk of a rotavirusrelated death was based on 2002 national data from the Instituto Nacional de Estadística Geografía e Informática (National Institute of Statistics, Geography, and Informatics, INEGI) (4). Approximately 2157 deaths due to diarrheal diseases occurred annually in children less than 5 years of age. By dividing these (2 157) by the population less than 1 year of age (2 056853$)$, the cumulative risk of a death due to AGE was calculated to be 1.05 deaths per 1000 live births. Since diarrheal mortality data were not specific to rotavirus, the proportion attributable to rotavirus was assumed to be the same as the proportion of hospitalizations attributed to rotavirus $(3,28)$. The cumulative risk of death due to rotavirus AGE (0.42 per 1000$)$ was calculated by multiplying the risk of death due to GE by the proportion of GE deaths attributed to rotavirus.

Disability-adjusted life years (DALYs). The disease burden of morbidity and mortality was also estimated in terms of DALYs (8). The DALY estimate included Years of Life Lost (YLL) due to premature mortality and Years Lived with Disability (YLD). The DALY loss from mortality (YLL) was calculated based on the average country-specific life expectancy at birth (29). The average life expectancy for males and females is 73.6 and 74.4 years, respectively. Only morbidity from disease severe enough to require medical care was considered for the calculation of YLD. Default disability weights from the global burden of disease study (8) and the World Health Organization's guidelines for cost-effectiveness studies (30) and estimated rotavirus illness duration of six days (31) were used to calculate YLD. A discount rate of $3 \%$ and age weighting were included (30) to ensure comparability.

Rotavirus vaccine efficacy and coverage. Estimates of the effectiveness of a complete vaccination course for rotavirus disease were based on the results of the phase III clinical trial of the liveattenuated human rotavirus vaccine (GSK Biologicals S.A., Rixensart, Belgium) that was given as two oral doses at 2 and 4 months of age. This was a multicenter trial conducted in 11 countries of Latin America, including Mexico.

The human attenuated rotavirus vaccine was first licensed in Mexico in July
2004 and made available to the private sector in January 2005. In March 2007, the vaccine was incorporated into the routine immunization schedule, first by the IMSS and later, in August 2007, by the Ministry of Health. Vaccine coverage has not yet reached the expected $90 \%$.

The efficacy of the human rotavirus vaccine to prevent rotavirus-related acute GE (requiring hospitalization) was $85 \%$ (32). Efficacy against outpatient visits was assumed to be $78 \%$. This represents the midpoint of $85 \%$ efficacy against rotavirus AGE (32) and 70\% efficacy against any rotavirus GE (33). Efficacy against death was assumed equal to that of the most severe cases requiring hospitalization (31). For the baseline analysis it was further assumed that one dose of the vaccine would have the same effectiveness as a full course during the interdosing period, as demonstrated by a clinical trial in Latin America (32). For the baseline analysis, it was further assumed that effectiveness would not decline in the second and subsequent years following vaccination.

It was assumed that children would receive the rotavirus vaccine at the same time as the diphtheria, tetanus, acellular pertussis, Haemophilus influenzae, inactivated polio vaccine (DTPa + Hib + IPV), and the hepatitis $B$ vaccine (HBV), which in Mexico are given at 2 months, 4 months, and 6 months of age. In the baseline analysis, national coverage of the third dose of DTP at 1 year of age for the year 2003 was estimated to be $92.8 \%$ (34). Rotavirus vaccination would occur with DTPa + Hib + IPV doses one and two; however, standardized data are only available for the coverage of the third dose (Table 1). As a result, this may be an underestimation of the actual coverage for doses one and two.

The effectiveness of vaccination was assessed by combining information on the expected vaccine coverage and timing of illness. An annual birth cohort was followed through the same age periods previously described. During each period, the number of outcomes in the absence of vaccination was estimated. The reduction in the number of outcomes during the same period was estimated based on the proportion of children with one or two doses, and the efficacy of one or two doses. The expected number of events averted prior to the 5th birthday was calculated as the sum of outcomes in each period. The global efficacy of the 
vaccine against severe rotavirus GE was also considered. For this reason, information on specific rotavirus serotypes was not considered in the analyses.

Vaccination costs. All costs are expressed in 2007 U.S. dollars. Vaccination costs included the cost of administering the vaccine, the price of each dose, the number of doses given (based on coverage level), and the expected waste losses from the vaccination program (10\%). The costs for administering the vaccine included the cost of health care personnel and training, cold chain, storage space, and public education. Mexico has the required infrastructure for running a national rotavirus vaccination program, based on its extensive history of administering oral polio vaccine. For this reason, the incremental administration costs are assumed to be low. A few studies estimate the cost of immunization for the current $\mathrm{WHO}$-recommended vaccines (35-38); however, no data was found on the incremental cost of adding another vaccine. Based on the range of estimates found in the immunization cost studies and the assumption that the incremental cost of administering an additional vaccine would be low, the model uses a cost of US\$ 1 per course. The public sector price per course of the vaccine (2 doses) was assumed to be US\$ 16 .

The vaccine price is a key variable in the cost-effectiveness estimates. For this reason, vaccine prices from US\$ 8-22 per course were assessed in sensitivity analysis. The cost of adverse events resulting from the vaccine were not included because its safety profile is similar to a placebo, therefore the cost, if any, would be negligible $(32,33)$.

Cost-generating outcomes. The economic burden of rotavirus disease in Mexican children was determined by combining the estimated number of each outcome with information on the costs associated with each. Cost generating outcomes were estimated based on three potential sources: the WHO CHOosing Interventions that are Cost Effective (WHO-CHOICE) project (39), physician interviews, and a multicenter hospitalbased rotavirus surveillance study done prior to a randomized vaccine trial (32).

The WHO-CHOICE project provides estimates of the per-diem cost of hospitals, outpatient visits, and health center visits for 14 epidemiological categories based on geographical region and mortality stratum. The per-diem and visit costestimates include items such as the cost of the facility, personnel, equipment, and food, and excludes items such as medications and diagnostic tests (40). All prices were adjusted for inflation (41). A hospital per-diem rate was estimated as an average of estimates for public primary, secondary, and tertiary-level facilities, using the proportions from the multicountry study (42). The cost of hospitalization was calculated as the product of the perdiem cost and a duration of 3.5 days (25, $43,44)$. Country-specific outpatient visit costs were developed by adjusting the WHO-CHOICE regional estimate proportionally to the country-specific hospital per-diem cost.

Six physicians were interviewed to characterize the typical management of rotavirus AGE. These physicians represented the public and private sectors and the IMSS. Interviews included questions regarding care for patients with moderate and acute rotavirus GE.

For the present analysis, resource utilization data were based on the surveillance study that was conducted in three Mexican cities (32), since these were considered to be the most reliable for Mexico. This surveillance study collected resource utilization and cost data in January-June 2003, which covers the months with the highest rotavirus incidence (December-January) and with the lowest (March-August) (32). Seven hospitals participated: three in the state of Mexico (two tertiary level and one secondary); two in Morelos (both tertiary level) and two in Durango (one tertiary level and one secondary level).

Health care costs. For this analysis, costs associated with episodes requiring hospitalization and outpatient visits were considered. Health care costs were calculated as the sum of the per-diem or per-visit cost, the cost of diagnostic tests, and the cost of medication. The hospital per-diem cost (US\$ 57.45) was estimated based on one public health care institution, the Hospital General de Tlalnepantla, which was considered to be representative of the public health sector and provided its actual per-diem cost. The cost-per-stay was calculated by multiplying the per-diem rate, which included hotel costs, food, and non-allied health personnel, by the mean length-ofstay (3.4 days). To ensure the estimate was representative, the mean length-ofstay was based on the average of 2.8 days (32) and 4 days (derived from physician interviews, 2003).

The cost-per-outpatient visit (US\$14.99) was calculated as the mean cost of visiting a pediatrician, emergency room, or rehydration room based on the proportion seen in each of three outpatient settings (derived from physician interviews, 2003). Approximately $30 \%$ of patients with rotavirus AGE visit a pediatrician; 30\%, an emergency room; $40 \%$, a rehydration room. Costs for these three types of outpatient visits were based on the average given by the Hospital General de Tlalnepantla.

Costs associated with diagnostic testing for rotavirus AGE were derived from estimates provided by the finance department of the Hospital General de Tlalnepantla. The total diagnostic costper-patient was calculated by taking the number of times a particular test is performed and multiplying it by its unit cost, and then summing the total cost of all the tests performed on a single patient. A mean diagnostic cost was calculated for both, inpatients (US\$ 6.27) and outpatients (US\$ 4.95). The most common diagnostic tests reported were blood counts, electrolytes, blood gas, and stool specimens.

Costs associated with medications were based on estimates provided by the pharmacy at the Hospital General de Tlalnepantla. The total medication cost per patient was calculated by multiplying the cost per dose of each medication used by the number of doses given and then, summing the total cost for all the medications given to a single patient. A mean medication cost was calculated for both inpatients (US\$ 9.63) and outpatients (US\$ 7.29). Medications included intravenous rehydration fluid, antiemetic, antifever, and antibiotic therapies. The input variables used to perform the base case analysis are described in Table 1.

\section{Sensitivity and uncertainty analyses}

For the present analysis, one-way sensitivity analysis of rotavirus disease-related and cost inputs was performed for different scenarios that are likely to influence the cost-effectiveness of vaccination (45). These scenarios included highand low-end estimates of vaccine price, disease incidence, and disease-related costs. Sensitivity analysis was performed 
TABLE 1. Input variables for a cost-effectiveness analysis of a rotavirus (RV) vaccination program in Mexico

\begin{tabular}{|c|c|c|}
\hline Variables & Baseline estimate & Data source \\
\hline \multicolumn{3}{|l|}{ Demographics } \\
\hline Birth cohort & 2285000 & PAHO, 2004 (9) \\
\hline \multicolumn{3}{|c|}{ Average life expectancy at birth (years) } \\
\hline Male & 73.6 & WHOSIS, 2000 (28) \\
\hline Female & 74.4 & \\
\hline \multicolumn{3}{|c|}{$\begin{array}{l}\text { Cumulative risk of outcomes for RV gastroenteritis } \\
\text { per } 1000 \text { children }<5 \text { years }\end{array}$} \\
\hline Outpatient visit rate & 265 & SSA, 2002 (21); IMSS, 2002 (22); extrapolation of five published studies (23-26) \\
\hline Hospitalization rate & 7 & SSA, 2002 (21); IMSS, 2002 (22); Velázquez et al., 2001/4 (3, 27) \\
\hline Mortality rate & 0.42 & SSA, 2002 (21); assumed RV proportion is the same as hospitalized \\
\hline \multicolumn{3}{|c|}{ Direct medical cost of RV gastroenteritis per patient ${ }^{\mathrm{a}}$} \\
\hline Ambulatory cases & US\$27.3 & Financial department of Hospital General de Tlalnepantla; physician interviews; \\
\hline Hospitalized cases & US\$ 174.2 & information not published \\
\hline \multicolumn{3}{|r|}{ 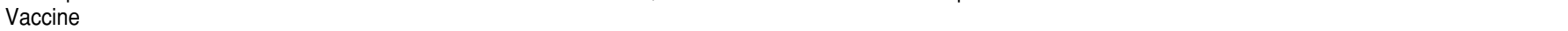 } \\
\hline Efficacy (RV outpatient visits) & $78 \%$ & Ruiz-Palacios et al., 2006 (31); De Vos et al., 2004 (32) \\
\hline Efficacy (RV hospitalization) & $85 \%$ & Ruiz-Palacios et al., 2006 (31) \\
\hline Efficacy (RV death) & $85 \%$ & Assumes efficacy is same as for hospitalizations (31) \\
\hline Coverage & $93 \%$ & CONAVA, 2003-4 (33) \\
\hline Administration cost (per course) & US\$1.0 & Author's assumption \\
\hline Price per course (2 doses) & US\$ 16.0 & Author's assumption \\
\hline
\end{tabular}

using the current price of US\$ 16 per course.

Additional results from the phase III clinical trial conducted in Latin America (32) suggest that the human rotavirus vaccine may reduce AGE of all causes, not limited to rotavirus, by $42 \%$ within the first year of life. Using age-distribution data for diarrhea disease, the vaccine efficacy against all causes of AGE was considered as a separate scenario in the sensitivity analysis.

An uncertainty analysis was conducted to help evaluate the potential impact of this uncertainty on preliminary quantitative estimates and to assess the need for additional data collection. The specific purposes included:

- assessing the range of likely outcomes of immunization based on the preliminary quantitative analysis;

- identifying specific variables that are likely to be important and may merit additional data collection; and,

- providing a preliminary framework for developing confidence intervals for final national estimates.

A Monte Carlo model was developed based on the preliminary model of rotavirus burden and immunization costeffectiveness described elsewhere $(5,6)$. In the Monte Carlo analysis, individual point estimates of parameters are replaced with distributions of potential values. Individual values are randomly se-

TABLE 2. Breakeven costs of rotavirus vaccine in Mexico using alternative criteria (best estimate and range) in 2007 US\$

\begin{tabular}{lcc}
\hline & \multicolumn{2}{c}{ US\$ / dose } \\
\cline { 2 - 3 } & Best estimate & $95 \% \mathrm{Cl}$ \\
\hline Breakeven cost & & \\
$\quad$ Direct, medical price & 5.10 & $4.11-6.66$ \\
Retail price (direct, indirect costs) & 6.24 & $5.49-8.47$ \\
& & \\
Cost effectiveness & & $50.78-78.94$ \\
gross national product & 64.37 & $10.02-14.46$ \\
\$1 000 (expanded oral rehydration therapy, water) & 11.74 & $7.86-11.49$ \\
\$550-800/DALYa (World Bank) & 9.15 & $4.44-7.07$ \\
\$175/DALY (WHO low income) & 5.16 & $3.69-6.26$ \\
\$75/DALY (HepB, Hib) & 4.36 & $3.34-5.90$ \\
\$30/DALY (Expanded Program on Immunization) & 4.00 & \\
\hline
\end{tabular}

a DALY: disability-adjusted life year.

b HepB: Hepatitis B; Hib: Haemophilus influenza type b.

lected from each of the distributions in a series of iterations, and results are calculated and stored. A new set of input values are then randomly selected and a new set of results are calculated and stored. The process is repeated for 10000 iterations. The final product is a distribution of potential outcomes that describe the likely range of actual expected results.

The output ranges developed through the uncertainty analysis are included in Table 2. In addition, the uncertainty analysis allows us to identify the parameters that contribute the most to uncertainty in the outcome estimates. For the cost-effectiveness analysis, uncertainty about diarrheal mortality and the por- tion attributable to rotavirus are additional key contributors to uncertainty.

\section{RESULTS}

\section{Disease burden and risk of rotavirus outcomes}

The estimated disease burden of rotavirus with and without a vaccination program in Mexico is presented in Table 3. Each year, due to rotavirus AGE, 1 in 4 children less than 5 years of age (265 per 1000$)$ required a clinic visit; 1 in 140 (7 per 1000 ) was hospitalized; and 1 in 2500 (0.4 per 1000$)$ died. An estimated 14 DALYs per 1000 births were lost to these outcomes. For the base case, the 
TABLE 3. Estimated disease burden of rotavirus in Mexico with and without a rotavirus vaccination program

\begin{tabular}{|c|c|c|}
\hline & Total annual events & $\begin{array}{l}\text { Events per } \\
1000 \text { children }\end{array}$ \\
\hline \multicolumn{3}{|l|}{ Without vaccination } \\
\hline Outpatient visits & 605525 & 265 \\
\hline Hospitalizations & 16086 & 7 \\
\hline Deaths & 923 & 0.40 \\
\hline$D_{A L Y s^{a}}$ & 31768 & 14 \\
\hline \multicolumn{3}{|l|}{ With vaccination } \\
\hline Outpatient visits & 190598 & 83.41 \\
\hline Hospitalizations & 2253 & 0.99 \\
\hline Deaths & 273 & 0.12 \\
\hline DALYsa & 9436 & 4.13 \\
\hline \multicolumn{3}{|c|}{ Benefit of vaccination (averted events) ${ }^{b}$} \\
\hline Outpatient visits & 414927 & 181.59 \\
\hline Hospitalizations & 13833 & 6.05 \\
\hline Deaths & 651 & 0.28 \\
\hline DALYs ${ }^{a}$ & 22331 & 9.77 \\
\hline
\end{tabular}

TABLE 4. Comparison of direct medical costs of treating gastroenteritis in Mexico using the hospital-based rotavirus surveillance study and alternative data, in 2007 US\$

\begin{tabular}{lccc}
\hline & $\begin{array}{c}\text { Hospital-based } \\
\text { surveillance } \\
\text { (US\$) data }\end{array}$ & $\begin{array}{c}\text { Alternative } \\
(\text { US } \$) 1^{\mathrm{a}}\end{array}$ & $\begin{array}{c}\text { Alternative } \\
(\text { US } \$) 2^{\mathrm{b}}\end{array}$ \\
\hline Hospitalization & & & 57.45 \\
Per-diem cost & 57.45 & 66.83 & 4.0 \\
Length of stay (days) & $3.4^{\mathrm{c}}$ & 3.5 & 229.80 \\
Total hotel cost & 195.32 & 233.91 & 27.04 \\
Diagnostics/medications & 15.90 & 77.19 & 256.84 \\
Total direct cost/hospitalization & 211.22 & 311.10 & 14.99 \\
Outpatient visit & 14.99 & 17.03 & 5.87 \\
$\quad$ Hotel cost & 12.24 & 11.07 & 20.86 \\
Diagnostics/medications & 27.23 & 28.10 & \\
Total direct cost/outpatient visit & & & \\
\hline
\end{tabular}

a Alternative 1: WHO-CHOICE and CVI data. These values were originally based on 2002 prices and were adjusted for inflation using the Consumer Price Inflation index (41).

${ }^{b}$ Alternative 2: Physician interview data.

${ }^{c}$ Average of 2.8 days (hospital-based surveillance study) and 4 days (physician interviews).

model predicts that rotavirus AGE is responsible for an annual 414927 (182 per 1000 ) outpatient visits; 13833 (6 per $1000)$ hospitalizations; and 651 (0.28 per $1000)$ deaths, all of which could be prevented by rotavirus vaccination. This represents an overall reduction of $69 \%, 86 \%$, and $70 \%$, respectively.

Costs of rotavirus disease. Based on the estimates derived from the hospitalbased rotavirus surveillance study (32), the total direct medical cost for inpatients was US\$211, with $92 \%$ of the cost attributed to hospitalization and the remainder due to the cost of diagnostics and medication. For outpatients, the total direct medical cost was US\$27, of which $55 \%$ was attributed to the cost of the visit (Table 4).
The costs of treating AGE using the hospital-based rotavirus surveillance study were similar to alternative costestimates. In Table 4, the inpatient and outpatient data estimates are compared to those using secondary data (WHOCHOICE and Children for Vaccine Initiative cost studies) and physician interviews. The total direct medical cost for hospitalization ranged from US\$211, using the hospital-based surveillance data, to US\$ 311, using secondary dataa total difference of US\$100. The difference between the high- and low-end estimates of total direct medical costs for outpatient visits was US\$ 7.24.

The estimated economic burden of rotavirus GE in Mexico and benefits of a rotavirus vaccine are shown in Table 5 . In the absence of vaccination, it was esti- mated that rotavirus AGE resulted in a total health care cost of over US\$ 19.6 million for each annual birth cohort, equivalent to US\$ 8.58 per child. Of these costs, $83 \%$ were associated with outpatient visits. Vaccination significantly reduced the economic burden of rotavirus AGE in Mexico, averting US\$ 14 million ( $71 \%$ of the total health care burden).

Cost-effectiveness of the rotavirus vaccination program. The estimates of the cost-effectiveness of a rotavirus vaccination program in Mexico are presented in Table 6 , and assume a basic vaccine price of US\$16 per course. The cost of the vaccination program includes the price of the vaccine and its administration. Moreover, the vaccination program cost assumes only the cost of vaccinating children who would receive the vaccine, based on vaccine coverage estimates and $10 \%$ wastage. Benefits are expressed as net medical costs from the health care system perspective and the cost-effectiveness ratio. All of these cost and benefit measures vary directly with vaccine price.

At a price of US\$ 16 per course (two doses), it would cost US\$25.4 million to vaccinate the Mexican birth cohort with the rotavirus vaccine (net medical costs). From the health care system perspective, a rotavirus vaccination program costs US\$ 1139 per DALY averted, US\$ 39102 per life saved, US\$ 1839 per hospitalization averted, and US\$ 61 per medical visit averted. Across all coursecosts less than or equal to US\$16, rotavirus vaccination was projected to be cost-effective, using the WHO criteria and a per-capita GDP of US\$ 6121 for Mexico (40).

\section{Sensitivity and uncertainty analyses}

The results of one-way sensitivity analyses are presented in Table 7 . The estimated medical cost per child is most sensitive to changes in assumptions regarding the incidence of rotavirus outpatient visits and the cost of outpatient treatment. A 25\% change in either of those parameters results in $11-21 \%$ change in the medical cost per child. The incremental cost-effectiveness rate estimates are affected by the rotavirus mortality rate, vaccine efficacy against mortality, and vaccine price. A $25 \%$ change in any of these variables results in $8-41 \%$ change in the incremental cost-effectiveness ratio. In addition, assuming a vaccine efficacy 
FIGURE 2. Cost-effectiveness of rotavirus vaccination in Mexico for alternative scenarios, in 2007 US\$

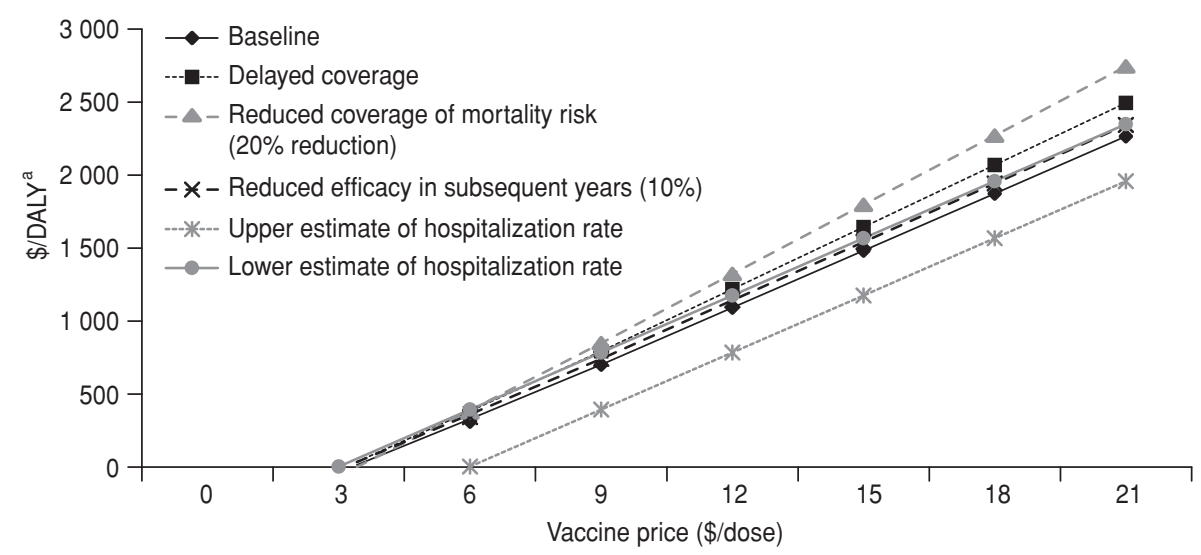

${ }^{a}$ DALY: disability-adjusted life year.

America, including Mexico (32). Rotavirus AGE results in a significant disease and economic burden from the perspective of the Mexican health care system. Rotavirus vaccination would prevent $70 \%$ of deaths due to rotavirus, $86 \%$ of associated hospitalizations, $69 \%$ of outpatient visits, and $70 \%$ of the associated DALYs. This compares to rates observed in other Latin American countries where rotavirus-associated mortality rates are lower $(46,47)$. Vaccination would also result in total, direct medical savings of US\$ 14 million, $71 \%$ of the overall health care burden (burden of all diseases).

Several criteria can be used for economic evaluations of a vaccination program. The appropriateness of the different approaches depends on the perspective of the policymaker. As an approximate benchmark and for comparison purposes only, we used the per-capita Gross Domestic Product (GDP) as a threshold and assumed that vaccination strategies that were less than this benchmark were potentially very cost-effective (46). With a per capita GDP of US\$ 6121 for Mexico (40) and a vaccine price of US\$ 16 per course, a national rotavirus vaccination program for Mexican children would be considered a very costeffective intervention since the cost per DALY averted is US\$ 1139 . It is important to emphasize that even if vaccination can be cost-effective, i.e., that the incremental cost-effectiveness ratio is less than the per capita GDP of a specific country, it may not be affordable without assistance. Future studies should focus their efforts on providing estimates of the financial costs to vaccinate a single birth cohort at different coverage rates.
Another criterion frequently used by national decision-makers is to compare the cost-effectiveness of a health intervention to the cost-effectiveness of other similar health interventions; in this case, other strategies for diarrhea prevention, child nutrition, and immunization. Ideally, the most cost-effective intervention would be chosen first. However, this type of country-specific information is not available in Mexico. Even if this information were available, comparing data across studies must be done with caution since there may be differences in the methods used.

Our analysis integrated empiricallycollected country-specific cost data with country-specific epidemiological estimates to develop the first national economic model of rotavirus vaccine introduction in Mexico. It complements other Regional efforts to develop further understanding of the value of a rotavirus vaccination program. These include two Regional studies $(5,6)$ and six countrylevel studies (46-51) that describe the disease and economic burden of rotavirus, and estimate the benefit and costeffectiveness of rotavirus vaccination at the Regional and country-levels.

A few study limitations need to be borne in mind. As shown by the sensitivity analysis, the rotavirus mortality rate and vaccine efficacy against death greatly affect the cost-effectiveness of vaccination. Although these variables are important to the results of the analysis, they have not been directly evaluated. Diarrheal deaths are generally recorded; however, vital statistics do not register the primary cause of diarrhea death as rotavirus. Moreover, the proportion of diarrheal deaths due to rotavirus is unknown. For this reason, it assumed that the proportion would be similar to hospitalized cases. Likewise, vaccine efficacy against death has been assumed to be the same as that for hospitalized cases, because death has not been evaluated as an outcome of a vaccine trial. Efforts should be made to empirically ascertain the incidence of death due to rotavirus AGE using active surveillance, especially in areas of the country where there is limited access to emergency treatment facilities.

The sensitivity analysis also demonstrated that the evaluation of health care resource utilization and its ascribed costs impact the health care costs associated with rotavirus AGE. Despite uncertainty in health care costs, the sensitivity analysis shows that varying costs by $25 \%$ has almost no effect on the cost-effectiveness of vaccination. Considering a societal perspective would therefore have made no difference in the cost-effectiveness of vaccination. Since it is possible that a child with AGE had a co-infection that required additional medications and diagnostic tests, there is some uncertainty about the actual cost of treating AGE. To avoid overestimating the medication and diagnostic costs, only the medications and diagnostic tests commonly used to treat AGE were included in the analysis. However, there is no way to be certain whether a specific antibiotic was prescribed to treat AGE or some other infection.

Another limitation is related to the availability of data on rotavirus disease treatment costs. Estimates of resource utilization were developed using a sample population in select facilities and medical treatment costs were derived from only one hospital. However, costs were varied by $25 \%$ in the sensitivity analysis. The sensitivity analysis shows that varying costs by $25 \%$ has almost no effect on the cost-effectiveness of vaccination. Alternative cost estimates were described in the paper for comparison, but were not used in the sensitivity analysis because there was uncertainty about the various methods used to derive these estimates.

In addition, outpatient visits were the main contributor to medical costs; however, outpatient and emergency room visits remain difficult to ascertain, especially because rotavirus AGE is not easily diagnosed in these settings in 
Mexico. These estimates could be improved with additional data and larger samples.

Additional study limitations are related to the coverage rate and timing of vaccination. Vaccine coverage is the proportion of children less than 5 years of age who would receive the rotavirus vaccine. The coverage is based on coverage rates of other vaccines (e.g., DTPa, $\mathrm{Hib}+\mathrm{IPV}$, and HBV), which may not be an accurate estimation of rotavirus vaccine coverage if a vaccine were to be introduced. In the analysis, we assumed that all groups within the country have equal likelihood of vaccination and all children would receive the vaccine at the recommended time. If high-risk populations were missed or vaccination were delayed, the effectiveness would be reduced. Since rotavirus GE occurs in young children and protection is conferred from the time of vaccine dose 1 until dose 2 is given (32), it is important that the vaccine be given on time. Future considerations should be made to account for the fact that not all children will receive the vaccine at the recommended time.

A final limitation of the study is the lack of data on the magnitude of herd immunity, which may be conferred by partial coverage of vaccination into a population. The analysis considered the direct effects of vaccination, but it did not consider the indirect protective effect on persons never vaccinated. The herd immunity effect could be large and might offset inefficiencies in delivery of a complete course, and on-time vaccination to all children.

In summary, rotavirus AGE results in a significant disease and economic burden in Mexican children. The results of this evaluation provide to policymakers strong evidence that supports the implementation of a national mass rotavirus vaccination program as a very cost-effective health care intervention in Mexico.

\section{REFERENCES}

1. Breese J, Glass RI, Ivanoff B, Gentsch J. Current status and future priorities for rotavirus vaccine development, evaluation, and implementation in developing countries. Vaccine. 1999;17:2207-22.

2. Kapikian AZ, Hoshino Y, Chanok RM. Rotaviruses. In: Knipe DM, Howley PM, et al., eds. Volume 1: Fields virology. 5th ed. Philadelphia: Lippincott Williams and Wilkins; 2007. Pp.1917-74.

3. Velázquez FR, Garcia-Lozano H, Rodriguez E, Cervantes Y, Gómez A, Melo M, et al. Diarrhea morbidity and mortality in Mexican children: Impact on rotavirus disease. Pediatr Infect Dis J. 2004;23(10):S149-55.

4. Instituto Nacional de Estadística Geografía e Informática, Secretaria de Salud. Dirección General de Información en Salud. Proyecciones de la población de Mexico, 2000-2050. CONAPO; 2002.

5. Rheingans RD, Constenla D, Antil L, Innis BL, Breuer T. Economic and health burden of rotavirus gastroenteritis for the 2003 birth cohort in eight Latin American and Caribbean countries. Rev Panam Salud Publica. 2007; 21(4):192-204

6. Rheingans RD, Constenla D, Antil L, Innis BL, Breuer T. Potential cost-effectiveness of vaccination for rotavirus gastroenteritis in eight Latin American and Caribbean countries. Rev Panam Salud Publica. 2007;21(4):205-16.

7. Gold MR, Siegel JE, Russell LB, Weinstein MC (Eds.). Cost-effectiveness in health and medicine. Oxford: Oxford University Press; 1996.

8. Murray CJL, Lopez AD. The global burden of disease: a comprehensive assessment of mortality and disability from diseases, injuries and risk factors in 1990 and projected to 2020. Cambridge: Harvard University Press; 1996.

9. Pan American Health Organization. Regional Core Health Data System-table generator 2004. Washington, D.C.: PAHO; 2004. Available from: http//www.pago.org/Project. asp? $\mathrm{SEL}=\mathrm{HD} \& \mathrm{LNG}=\mathrm{ENG} \& \mathrm{ID}=379$. Accessed 6 August 2004.
10. Barraza $P$, Avendano LF, Spencer E, Calderon A, Prenzel I, Duarte E. Hospital infection caused by rotaviruses in infants, Santiago, Chile. Bol of San Panam. 1986;101:328-38.

11. Bok K, Castagnaro N, Borsa A, Nates S, Espul C, Fay O, et al. Surveillance for rotavirus in Argentina. J Med Virol. 2001;65:190-8.

12. Bok K., Castagnaro NC, Diaz NE, Borsa A, Cagnoli MR, Nates S, et al. Rotavirus laboratory network: results after one year of observation. Rev Argent Microbiol. 1999;31:1-12.

13. Cardoso DDP, Soares CMA, Souza MBLD, Azevedo MSP, Martins RMB, Queiroz DAO, et al. Epidemiological features of rotavirus infection in Goiânia, Goiás, Brazil, from 1986 to 2000. Mem Inst Oswaldo Cruz. 2003;98:25-9.

14. González FS, Sordo ME, Rowensztein G, Sabbag L, Roussos A, De Petre E, et al. Rotavirus diarrhea. Impact in a pediatric hospital of Buenos Aires. Medicina (B Aires). 1999;59(4): 321-6.

15. Gomez JA, Sordo ME, Gentile A. Epidemiologic patterns of diarrheal disease in Argentina: estimation of rotavirus disease burden. Pediatr Infect Dis J. 2002;21:843-50.

16. Perez-Schael I, Gonzalez R, Fernandez R, Alfonzo E, Inaty D, Boher $Y$, et al. Epidemiological features of rotavirus infection in Caracas, Venezuela: Implications for rotavirus immunization programs. J Med Virol. 1999; 59:520-6.

17. Urrestarazu MI, Liprandi F, De Suarez EP, Gonzalez R, Perez-Schael I. Etiological, clini$\mathrm{cal}$, and sociodemographic characteristics of acute diarrhea in Venezuela. Pan Am J Public Health 1999;6:149-56.

18. Velázquez FR, Matson DO, Guerrero ML, Shults J, Calva JJ, Morrow AL, et al. Serum antibody as a marker of protection against natural rotavirus infection and disease. J Infect Dis. 2000;182:1602-9.

19. Villa S, Guiscafre H, Martinez H, Munoz O, Gutierrez G. Seasonal diarrheal mortality among Mexican children. Bull WHO. 1999;77: $375-80$.
20. Velázquez FR, Calva JJ, Guerrero ML, Mass D, Glass RI, Pickering LK, et al. Cohort study of rotavirus serotype patterns in symptomatic and asymptomatic infections in Mexican children. Pediatr Infect Dis J. 1993:12:54-61.

21. Secretaría de Salud/Servicio Social de Salud. Anuario estadístico 2000-2001. In: Sistema Nacional de Información en Salud, 2001-2002. Ciudad de México: Ministerio de Salud; 2002.

22. Instituto Mexicano del Seguro Social. Estadísticas: Daños y egresos hospitalarios 2002. In: Dirección de prestaciones médicas: Información estadística en salud, 2002. Ciudad de México: Ministerio de Salud; 2002.

23. O'Ryan M, Pérez-Schael I, Mamani N, Peña A, Salinas B, Gonzales G, et al. Rotavirusassociated medical visits and hospitalizations in South America: a prospective study at three large sentinel hospitals. Pediatr Infect Dis J. 2001;20:685-93.

24. Ehrenkranz P, Lanata CF, Penny ME, SalazarLindo E, Glass RI. Rotavirus diarrhea disease burden in Peru: the need for a rotavirus vaccine and its potential cost savings. Rev Panam Salud Publica. 2001;10:240-8.

25. Guardado JAA, Clara AW, Turcios RM, Fuentes RAC, Valencia D, Sandoval R, et al. Rotavirus in El Salvador-an outbreak, surveillance and estimates of disease burden 2000-2002. Pediatr Infect Dis J. 2004;23(10): S156-60.

26. Salinas B, Gonzalez G, Gonzalez R, Escalona M, Materan M, Perez-Schael I. Epidemiologic and clinical characteristics of rotavirus disease during five years of surveillance in Venezuela. Pediatr Infect Dis J. 2004;23:S161-7.

27. World Health Organization. International statistical classification of diseases and health related problems: ICD-10. Second edition. Geneva: WHO; 2005.

28. Velázquez FR, Castellanos A, Luna G, Bustamante ME, Gómez A, Cedillo R, et al. Importancia de los agentes virales como causa de diarrea grave en los niños menores de cinco años de edad que requieren hospitalización, y 
factores de riesgo asociados. $1^{\text {a }}$. Ed.: Sestante, S.A. de C.V. In: Las múltiples facetas de la investigación en salud: Proyectos estratégicos del Instituto Mexicano del Seguro Social. Ciudad de México: Instituto Mexicano del Seguro Social; 2001. Pp. 133-52.

29. World Health Organization, WHO Statistical Information System (WHOSIS). Life tables for 191 countries. Geneva: WHO; 2001. Available from: http://www3.who.int/whosis/menu. cfm?path=whosis,bod,burden_statistics, life \&language =english. Accessed 21 October 2004.

30. Baltussen R, Adam $\mathrm{T}$, Tan Torres $\mathrm{T}, \mathrm{Hu}-$ tubessy R, Acharya A, Evans D. Generalized cost effectiveness analysis: a guide. Geneva: World Health Organization; 2002.

31. Liddle JL, Burgess MA, Gilbert GL, Hanson RM, McIntyre PB, Bishop RF, et al. Rotavirus gastroenteritis: impact on young children, their families and the health care system. Med J Aust. 1997;167:304-7.

32. Ruiz-Palacios GM, Pérez-Schael I, Velázquez FR, Abate H, Breuer T, Clemens SC, et al. Safety and efficacy of an attenuated vaccine against severe rotavirus gastroenteritis. $\mathrm{N}$ Engl J Med. 2006;354(1):11-22.

33. De Vos B, Vesikari T, Linhares AC, Salinas B, Perez-Schael I, Ruiz-Palacios GM, et al. A rotavirus vaccine for prophylaxis of infants against rotavirus gastroenteritis. Pediatr Infect Dis J. 2004;23(10 suppl):S179-82.

34. Mexico, Consejo Nacional de Vacunación (CONAVA). Informes trimestrales de vacunación y vigilancia nutricional. Available from: http:/ / www.conava.gob.mx. Accessed 3 November 2004.

35. Brenzel L, Claquin P. Immunization programs and their costs. Soc Sci Med. 1994;39: $527-36$.
36. Miller MA, McCann L. Policy analysis of the use of hepatitis b, haemophilus influenzae type b, streptococcus pneumoniae-conjugate and rotavirus vaccines in national immunization schedules. Health Economics. 2000;9:19-35.

37. Walker D, Mosqueira NR, Penny ME, Lanata $\mathrm{CF}$, Clark AD, Sanderson CFB, et al. Variation in the costs of delivering routine immunization services in Peru. Bull WHO. 2004;82:676-82.

38. Waters HR, Dougherty L, Simon-Pierce T, Tran N, Wysonge CS, Long K, et al. Coverage and costs of childhood immunizations in Cameroon. Bull WHO. 2004;82:668-75.

39. World Health Organization. CHOosing Interventions that are Cost Effective (WHOCHOICE). Prices for hospitals and health centres. Available from: http://www3.who.int/ whosis/cea/prices/unit.cfm?path=evidence, cea,cea_prices,cea_prices_unit\&language $=$ english. Accessed 20 January 2004.

40. World Bank Group. World development indicators online 2004. Available from: http:// www.worldbank.org/data/wdi2004/. Accessed 16 August 2004.

41. U.S. Department of Labor, Bureau of Labor Statistics. Inflation and consumer spending, 2003. Available at: http://www.bls.gov/bls/ inflation.htm. Accessed 19 August 2004.

42. Adam T, Evans DB, Murray JL. Econometric estimation of country-specific hospital costs. Cost Eff Resour Alloc 2003;1(3). Available at http://www3.who.int/whosis/cea/ background documents/pdf/Unitcost.pdf

43. Bittencourt SA, Leal Mdo C, Santos MO. Hospitalization due of infectious diarrhea in Rio de Janeiro State. Cad Saude Publica. 2002; 18(3):747-54.

44. Gomez JA, Nates S, De Castagnaro NR, Espul C, Borsa A, Glass RI. Anticipating rotavirus vaccines: review of epidemiologic studies of rotavirus diarrhea in Argentina. Rev Panam Salud Publica. 1998;3(2):69-78.

45. Baltussen R, Hutubessy R, Evans D, Murray C. Uncertainty in cost-effectiveness analysis: probabilistic uncertainty analysis and stochastic league tables. Int J Technol Assess Health Care. 2002;18(1):112-9.

46. Constenla D, O'Ryan M, Navarrete M S, Antil L, Rheingans R D. Potential cost effectiveness of a rotavirus vaccine in Chile. Rev Méd Chile 2006;134:679-88.

47. Constenla D, Pérez-Schael I, Rheingans RD, Antil L, Salas H, Yarzábal JP. Evaluación del impacto económico de la vacuna antirrotavírica en Venezuela. Rev Panam Salud Pública. 2006;21(4):213-22.

48. World Health Organization. The world health report 2002-reducing risks, promoting healthy life. Geneva: WHO; 2002. Pp. 108.

49. Constenla D, Ortega E, Rheingans R, Antil L, Saez-Llorens X. Impacto económico de la vacuna antirrotavírica en Panamá. Anales de Pediatria 2008;68(2):128-35.

50. Constenla D, Rivera M, Rheingans RD, Antil L, Vásquez ML. Evaluación económica de una eventual incorporación de la vacuna antirotavirus en el calendario de vacunación infantil en Honduras. Rev Med Hond. 2006;74(1):19-29.

51. Constenla D, Linhares A, Rheingans RD, Antil L, Waldman EA, da Silva LJ. Economic impact of a rotavirus vaccine in Brazil. J Health Pop Nutrition 2008. [In press].

Manuscript received on 24 March 2008. Revised version accepted for publication on 24 August 2008.

RESUMEN Objetivos. Evaluar el costo y los beneficios de un programa nacional de vacunación infantil contra el rotavirus en México.

\section{Impacto económico de un programa de vacunación contra rotavirus en México}

Palabras clave
Métodos. Se diseñó un modelo de análisis de decisión, desde la perspectiva del sistema de salud mexicano, para comparar dos alternativas: vacunar contra el rotavirus o no vacunar. A partir de datos nacionales publicados se estimó el número de casos y muertes por rotavirus, los años de vida ajustados por la discapacidad (AVAD) que se evitarían y la relación costo-efectividad incremental (US\$/AVAD) de una cohorte anual hipotética de 285000 niños; se partió de algunos supuestos sobre el costo, la cobertura y las tasas de eficacia.

Resultados. Con una cobertura de $93 \%$ y un precio de la vacuna de US\$16,00 por esquema (dos dosis), se estima que un programa de vacunación contra rotavirus en México evitaría 651 muertes (0,28 muertes por 1000 niños), 13833 hospitalizaciones (6,05 hospitalizaciones por 1000 niños) y 414927 visitas de consulta externa (182 consultas por 1000 niños) por gastroenteritis aguda asociada a rotavirus (GAR). La vacunación podría reducir la carga económica por GAR en México al evitar gastos por US\$ 14 millones (71\% de la carga total por atención sanitaria). A un precio de US\$ 16,00 por esquema, la relación costo-efectividad sería de US\$ 1 139,00 por AVAD evitado. Una reducción en el precio del programa de vacunación contra rotavirus (US $\$ 8,00$ por esquema) generaría una menor relación costo-efectividad incremental de US\$303,00 por AVAD evitado.

Conclusiones. Un programa nacional de vacunación contra rotavirus en México reduciría la incidencia y la mortalidad infantiles y sería altamente efectivo en función del costo, según los umbrales de las intervenciones de costo-efectividad de la Organización Mundial de la Salud.

Rotavirus, vacunas contra rotavirus, análisis costo-beneficio, inmunización masiva, gastroenteritis, México. 